\title{
Impact of Time Spent in Parents-Children Communication on Children Misconduct
}

\author{
${ }^{1}$ Nurani Kamaruddin, ${ }^{1}$ Siti Zobidah Omar, ${ }^{2}$ Salleh Hassan, \\ ${ }^{3}$ Musa Abu Hassan, ${ }^{2}$ Arnida Ayu Che Mee and ${ }^{1}$ Jeffrey Lawrence D'Silva \\ ${ }^{1}$ Institute for Social Science Studies, \\ ${ }^{2}$ Faculty of Modern Language and Communication, \\ University Putra Malaysia, 43400 Serdang, UPM, Malaysia \\ ${ }^{3}$ University Sains Islam Malaysia, Bandar Baru Nilai, 71800, Nilai, Negeri Sembilan, Malaysia
}

Received 2012-02-22, Revised 2012-08-19; Accepted 2012-09-01

\begin{abstract}
Communication is a must and family communication enhances family ties. This study is design to discover whether quantity of time spent between parents and children have a direct impact on children misconduct activities. This is a quantitative study using a survey questionnaire. Data were gathered from 1163 respondents which comprised of 641 secondary school children and 522 parents and were analyzed using SPSS software. The data collection process took three months to be completed. The outcome showed that the children perceive the amount of time spent with their parents does have an impact towards their misconduct activities. However, it was not the same for the parents. It seems that parents did not perceive that the amount spent for communicating with their children will affect their children's misconduct activities. Parents should pay more attention to the time that they spent with their children as their children value the time that they spent with their parents'. It is crucial for parents to allocate some time in their hectic schedule to communicate with the children so that the children would not feel neglected and left out by their own parents thus making them prone to unhealthy activities.
\end{abstract}

Keywords: Family Communication, Children Misconduct

\section{INTRODUCTION}

Communication activities occupy most of our daily agenda. People communicate for various reasons such as to get new acquaintances, to get explanation, to give directions, to seek advice, to share their thoughts and so on. However, the main reason for communication is to get or to share information. According to Elias and Noordin (2011) good communication is pertinent as it will lead towards gaining more information among people. O'Hair (1998) stated that the essence of communication in all contexts is that people exchange messages to accomplish goals and objectives. Communication process is achievable when both party mutually understand the message conveyed as stated by Segrin and Flora (2005), communication relies on intersubjectivity whereby it refers to shared meaning created, or a state where a person understands the other and is understood by the other. However, according to Poole et al. (2000) communication is not a neutral act of moving content from one person to another, but rather a complex transaction influenced by numerous factors. As a process, communication is an ongoing, complex and changing activities (Segrin and Flora, 2005).

Communication is not just limited to verbal action but it also encompasses of the non-verbal actions. Even when verbal communication is missing, unintentional messages still constitute communication. Most of the time, it's the non-verbal communication that speaks louder than the spoken words. Non-verbal communication is the way our body behaves to complement our verbal communication and sometimes our body language might betray our verbal communication message (Knapp and Hall, 2009). Thus, it is important for us to use the right body gestures to enhance our verbal message in order to get our meanings successfully understood by the receiver.

On the other hand, family communication is defined as the act of making information, ideas, thoughts and feelings known among members of a family unit Coressponding Author: Nurani Kamaruddin, Institute for Social Science Studies, Universiti Putra Malaysia, 43400 Serdang, UPM, Malaysia 
(Smith et al., 2009). The process of family growth has a lot to do with the ability of all the family members to communicate with one another. Clark and Shields (1997) stated that communication is fundamental in interpersonal relationships between family members and it serves as the main key to understand the relation that developed within family. Many studies have shown that communication is a facilitator of family functioning (Smith et al., 2009). According to Mastura and Hamzah (2007), communication in family is a two way communication (giving and taking) verbally or nonverbal where a functional family will accept and try to comprehend the message delivered whether vague or clear between others, while a dysfunctional family rarely accept the message properly, in fact it is being ignored. Smith et al. (2009) stated that, a family that has positive family communication will be better able to alter their cohesion and flexibility to meet developmental and situational demands that arise, whereas family system with poor communication tends to have lower functioning in regards to cohesion and flexibility.

There is no unitary formula for good communication and there is no one right way to communicate for family life to function well. However, according to Bernard and Fenton (2007), the best way to communicate in family is to arouse the feeling of sharing and listening. Message delivered must be clear and appropriate. Good family communication involves being both an active listener and a thoughtful speaker. Findings by Salleh et al. (2009) have laid seven criteria to develop quality communication, which are: openness, transparency, honesty, clear (clarity), communicate as friend, doing activities and spending time together. Several past research also have come up with communicative relational standards that include showing affection (Baucom et al., 1996; Fletcher et al., 1999; Vangelisti and Daly, 1997; Caughlin, 2003); providing emotional support (Fletcher et al., 1999; Vangelisti et al., 1999; Caughlin, 2003) and having sense of humor (Fletcher et al., 1999; Vangelisti et al., 1999; Caughlin, 2003).

Basically, family communication operates within two types of family communication climate which are conformity orientation and conversation orientation (McLeod and Chaffee, 2007). Conformity orientation refers to the degree to which families create a climate that stress homogeneity of attitude, values and beliefs (high conformity) versus heterogeneous attitudes and beliefs, greater individuality and uniqueness and independence of family members (low conformity; Koerner and Fitzpatrick, 1997). Meanwhile conversation orientation refers to the degree to which family members create a climate where all are encourage to participate freely and frequently in interaction without limitation regarding time spent and topic discussed (high conversation) versus less frequent interaction with only a few topics that are freely discussed (low conversation; Koerner and Fitzpatrick, 1997). High conversation families share a lot of activities, thoughts and feelings (Koerner and Fitzpatrick, 2004).

Parents who create communication gaps between the children will make their children feel at a loss, a situation whereby the children will finally self-destruct. Past research showed that communication problem between parents and children is one of the factors that make children feel lonely and depressed (Hartos and Power, 2000). These feelings of loneliness and depressed will eventually result in those children being involved with social illness such as drug abuse, theft, fights and so forth as a way to express their feelings. Psychologists agreed adolescent years that must be endured by the youth is certainly a time of storm and stress because they were going through physical and emotional changes due to biological changes which is of natural process that happens to all individual that have gone through the change phases from childhood years to the adulthood (Rathus, 2010). However, communication process that allows an open and honest practice is a perfect medium for the children to share their problems or to voice out their ideas without them being scared. This eventually will develop positive values in the children thus making them a difficult target for those with bad intention as stated by Barberet and Fisher (2009) who identify that close relationship between parent and children could hinder teenagers' misconduct.

Time for family communication is the most common problem faced by family today. Almost every parent is a working parent, who spends long working hours at the workplace for the sake of providing for the family. Meanwhile, the children routine life is lined up with strenuous academic activities, thus making it harder for parents and children to catch up with each other. Back in the 1970 's, the term quality time emerged when many mothers started going to study (Emmers-Sommer, 2004). They were told that quality time with their children is what matters more instead of the quantity of time (Lingren, 1998; Emmers-Sommer, 2004). Quality time refers to focused, uninterrupted time with partners, friends, or children where it should provide opportunity for meaningful conversation and the chance to do worth-while activities together (Lingren, 1998). According to Segrin and Flora (2005), the quality of time family members spend together says far more about their relationships than does the quantity of time spent together.

A study by Sandberg and Hofferth (2001) regarding how much time family members spend together found that American children spent more time with their mother and no less time with their father. According to Alwin (1996), probably the strongest explanation for 
why parents and especially mothers are spending more time with their children is pertaining to child rearing trends. It has been established that the frequency of interacting with children will enhance the parent-children relationship. Time spent in family activities is assumed to promote positive relationship and individual development. Sandberg and Hofferth (2001) found that children who spent more hours eating meals with their family had lower level of behavior problems than did those who spent fewer hours eating together. According to Jolly (2007), the intimate relationships that develop between parents and children will give them comfort for sharing problems, feelings, hopes and also ideas.

Previous studies showed that family communication and children misconduct does relate with each other. Many past researches have found that communication between parents and children is one of the important factors that could prevent children from being involved in social problems, an increment in communication intimacy between parent and children can help reduce misconduct among the children (Clark and Shields, 1997). Klein et al. (1997) also showed that communication between parent and children is one of the variables that have connection with the increase or decrease in teenagers' misconduct. According to Hartos and Power (2000), communication between parent and children have connection with children's positive behaviours such as academic excellence and also children's' negative behaviours such as drug abuse, alcoholism and other misconducts. While Barberet and Fisher (2009) finds that close relationship between parent and children could hindered teenagers misconduct. Hence, the objective of this study is to determine whether quantity of time spent between parents and children have a direct impact on their misconduct activities.

\section{MATERIALS AND METHODS}

This research utilized quantitative method using selfadministered questionnaire with drop and pickup method. There were two set of questionnaire prepared for this purpose, one is for the children and the other for the parents. The set were identical except for the wording to reflect the belonging of the statement to the children and parents. A total of 1163 respondents were involved in this study that comprised of 641 children and 522 parents. Respondents were selected from seven secondary schools in Kuala Lumpur area. Sample selection was based on stratified clustered sampling. The criteria used for respondent selection were based on school grade, total number of student, mixed school and there are three ethnic groups at the school. Only grade A and grade B school with total of students exceeding 1500 were selected as sample for this study. Later, the respondents were selected based on students ratio according to race: 5:4:1-Malay:Chinese:Indian. Students were asked to completed the children set and bring back the parents set to be completed by their either the mother or father. They were given a week to complete the set before it will be picked up by the research team. Data were analyzed using SPSS software. Descriptive statistics were used to describe the demographic profile and inferential statistics were used to answer the objectives of the study.

\section{RESULTS}

Table 1 describes about the demographic profile of the respondent (parents-children).There are 522 parent's respondents and 641 children respondents involved in this study. Half of the sample for parent's respondents accounted for male $(54.9 \%)$; meanwhile for children respondents it is the female being the highest with $50.7 \%$. The highest response according to race for both parents and children are Malay, followed by Chinese and Indian; for parents, Malay (56.9\%), Chinese $(32.8 \%)$ and Indian $(10.3 \%)$. While for children; Malay $(55.6 \%)$, Chinese $(31.9 \%)$ and Indian (12.5\%). The figures are in accordance with the respondents ratio according to ethnic group decided earlier.

It seems that from the parents and children answer, most of them is a working father $(76.6 \%)$ and have a working father $(92.0 \%)$. However, this does not apply for the mother's working situation. Half of the mother answered that they are a working mother (50.2\%), but only $36.7 \%$ children answered that they have a working mother. This may imply that maybe some of the children do not know what their mother do for living or there is a lack of communication between mother and children regarding what their mother do. Finally, most of respondents of this study $(61.4 \%$; parents and $57.5 \%$; children) have a small number of family members with one to three children/siblings living together.

\subsection{Parents-Children Interaction Time}

Parents-children interaction time is studied from two time frame; which are during weekdays and during weekends and further divided between father and mother. From Table 2 it can be seen that the father interaction with the children surpass the mother for a period of less than one hour and up to five hours during weekdays (81.4\% Vs 76.4\%) and weekends $(57.2 \%$ Vs $56.2 \%)$. 
Nurani Kamaruddin et al. / American Journal of Applied Sciences 9 (11) (2012) 1818-1823

Table 1. Parents-children demographic profile

\begin{tabular}{|c|c|c|c|c|}
\hline \multirow[b]{2}{*}{ Demographic Profile } & \multicolumn{2}{|c|}{ Parents $(n=522)$} & \multicolumn{2}{|c|}{ Children $(n=641)$} \\
\hline & Frequency & $(\%)$ & Frequency & $(\%)$ \\
\hline Gender & & & & \\
\hline Male & 303 & 54.9 & 316 & 49.3 \\
\hline Female & 249 & 45.1 & 325 & 50.7 \\
\hline Race & & & & \\
\hline Malay & 307 & 55.6 & 365 & 56.9 \\
\hline Chinese & 176 & 31.9 & 210 & 32.8 \\
\hline Indian & 69 & 12.5 & 66 & 10.3 \\
\hline $\begin{array}{l}\text { Working Father } \\
\text { Yes }\end{array}$ & 423 & 766 & 500 & 070 \\
\hline No & 129 & 23.4 & $\begin{array}{r}51 \\
51\end{array}$ & 8.0 \\
\hline $\begin{array}{l}\text { Working Mother } \\
\text { Yes }\end{array}$ & 277 & 502 & 235 & \\
\hline No & 275 & 49.8 & 406 & 63.3 \\
\hline $\begin{array}{l}\text { Number of } \\
\text { children living } \\
\text { together/siblings }\end{array}$ & & & & \\
\hline $1-3$ & 339 & 61.4 & 368 & 57.5 \\
\hline 4-6 & 204 & 36.9 & 249 & 38.8 \\
\hline $7-10$ & 9 & 1.7 & 24 & 3.7 \\
\hline
\end{tabular}

Table 2. Parent-Children interaction time during weekdays and weekend

\begin{tabular}{|c|c|c|c|c|}
\hline \multirow{2}{*}{$\begin{array}{l}\text { Interaction } \\
\text { time }\end{array}$} & \multicolumn{2}{|l|}{ Father } & \multicolumn{2}{|l|}{ Mother } \\
\hline & Frequency & $(\%)$ & Frequency & $(\%)$ \\
\hline Weekdays & & & & \\
\hline$<1 \mathrm{~h}$ & 192 & 34.8 & 201 & 36.4 \\
\hline 1. $1-3 \mathrm{~h}$ & 147 & 26.6 & 132 & 23.9 \\
\hline 3. $1-5 \mathrm{~h}$ & 111 & 20.0 & 89 & 16.1 \\
\hline 5. $1-7 \mathrm{~h}$ & 48 & 8.7 & 62 & 11.2 \\
\hline 7. $1-9 \mathrm{~h}$ & 23 & 4.2 & 34 & 6.2 \\
\hline 9. $1-11 \mathrm{~h}$ & 18 & 3.3 & 11 & 2.0 \\
\hline$>11.1 \mathrm{~h}$ & 13 & 2.4 & 23 & 4.2 \\
\hline $\begin{array}{l}\text { Weekends } \\
<1 \mathrm{~h}\end{array}$ & 97 & 176 & 103 & 187 \\
\hline 1. $1-3 \mathrm{~h}$ & 142 & 25.7 & 134 & 24.3 \\
\hline 3. $1-5 \mathrm{~h}$ & $7 \overline{7}$ & 13.9 & 73 & 13.2 \\
\hline 5. $1-7 \mathrm{~h}$ & 84 & 15.3 & 78 & 14.1 \\
\hline 7. $1-9 \mathrm{~h}$ & 49 & 8.9 & 44 & 8.0 \\
\hline 9. $1-11 \mathrm{~h}$ & 26 & 4.7 & 34 & 6.1 \\
\hline$>11.1 \mathrm{~h}$ & 77 & 13.9 & 86 & 15.6 \\
\hline
\end{tabular}

However, mother's total interaction time (weekdays and weekend) with the children is the longest as compared to the father. Mother spent $23.6 \%$ for interaction time for period of more than five hours and up to more than eleven hours during weekdays and $43.8 \%$ during weekends as compared $18.6 \%$ by father during weekdays and $42.8 \%$ during weekends.

\subsection{Parents' Perception of Children Misconduct Activities Versus Children Involvement}

There were 26 types of misconduct listed whereby it was later classified into ten categories. The category can be seen as in Table 3 namely; school-related, gamblings, internet/computer-related, substance abuse, violent crime, theft, sexual offence, vandalisme, gang related and others.
Table 3. Parents' perception of children misconduct activities versus children involvement

\begin{tabular}{lllll}
\hline & Parents $(\mathrm{n}=522)$ & \multicolumn{2}{l}{ Children $(\mathrm{n}=641)$} \\
Category of & --------- & S.D \\
misconduct & Mean & S.D & Mean & S. \\
\hline School related & 1.1839 & 0.356510 & 1.2668 & 0.45244 \\
Gamblings & 1.1743 & 0.486150 & 1.3526 & 0.61342 \\
Internet/computer & 1.1485 & 0.385050 & 1.1747 & 0.46340 \\
related & & & & \\
Substance abuse & 1.1169 & 0.295280 & 1.1642 & 0.43688 \\
Violent crime & 1.0910 & 0.229970 & 1.2184 & 0.40757 \\
Theft & 1.0690 & 0.289010 & 1.1513 & 0.47157 \\
Sexual offence & 1.0565 & 0.319200 & 1.3432 & 0.65966 \\
Others & 1.0453 & 0.235180 & 1.3779 & 0.50700 \\
Vandalisme & 1.0369 & 0.197650 & 1.1037 & 0.42638 \\
Gang related & 1.0297 & 0.019976 & 1.1456 & 0.40045 \\
\hline
\end{tabular}

Table 4. Level of Misconduct

\begin{tabular}{lrll}
\hline Level & \multicolumn{1}{c}{ (\%) } & Mean & S.D. \\
\hline Parents perspective & & 1.0690 & 0.268 \\
Low (1-1.33) & 93.5 & & \\
Moderate (1.34-2.66) & 6.1 & & \\
High (2.37-4) & 0.4 & & \\
Children involvement & & 1.2137 & 0.454 \\
Low (1-1.33) & 80.5 & & \\
Moderate (1.34-2.66) & 17.6 & & \\
High (2.37-4) & 1.9 & & \\
\hline
\end{tabular}

Table 5. Correlation between misconduct and interaction time

\begin{tabular}{lll}
\hline Variables & $\mathrm{r}$ & $\mathrm{p}$ \\
\hline Children's views (n=641) & & \\
Children-Father (Schooldays) & -0.076 & 0.053 \\
Children-Father (Weekend) & -0.104 & 0.008 \\
Children-Mother (Schooldays) & -0.110 & 0.005 \\
Children-Mother (Weekend) & -0.134 & 0.001 \\
Parents' views (n = 522) & & \\
Father- Children (Schooldays) & -0.021 & 0.636 \\
Father-Children (Weekend) & -0.033 & 0.448 \\
Mother-Children (Schooldays) & -0.011 & 0.796 \\
Mother-Children (Weekend) & -0.035 & 0.420 \\
\hline
\end{tabular}

Of those listed, the top three highest category of children misconduct perceived by parents is school related $(\mathrm{M}=1.1839)$, this is followed by gamblings $(\mathrm{M}=$ $1.1743)$ and internet/computer related $(M=1.1485)$. It seems that the parents perception is quite differ from the actual involvement by children. According to the children, the highest category of misconduct by them is others $(\mathrm{M}=1.3779)$ which is falled under the eight ranking in the parents perception. Others is represented by involvement in illegal street racing, running away from home and being cruel towards animal. This was followed by gamblings $(\mathrm{M}=1.3526)$ and surprisingly sexual offense $(\mathrm{M}=1.3432)$ is the third highest category of misconduct involved by the children. This requires immediate attention by the parents as it will evolve into other serious matters in the future. 


\subsection{Level of Youth Misconduct}

Overall, in this study it was identified that the level of misconduct (refer to Table 4) from the parent's perspective $(\mathrm{M}=1.069)$ and the children involvent $(\mathrm{M}=$ 1.2137) is low. This is considered a good findings for this study. However, there is still a need to plan for preventive action so that it will not escalate into moderate or high level.

\subsection{Interaction Time and Children Misconduct}

Table 5 shows the relationship between interaction time and youth misconduct. It seem that from the children's perspective, there is a significant negative correlation for the three variables which are childrenfather (weekend), children-mother (school days) and children-mother (weekend). The negative correlation indicates that interaction time has an inverse connection with misconduct which means that if the higher the interaction times, the lesser the tendency for the children to be involved with misconduct activities. It was not surprising to see that there is no connection between children-father interactions during schooldays as we have noted earlier on that children do spend more time interacting with their mothers during school days.

However, it was interesting to see that parents' overall do not perceive that interaction time will correlate to their children's misconduct activities. This is something that needs a serious attention by all the parents as many past researches have established that the frequency of interacting with children will enhance the parents-children relationship. This is supported by Jolly (2007) where intimate relations develop between parents and children will give them comfort for sharing problems, feelings, hopes and also ideas.

\section{DISCUSSION}

The study showed that parents failed to see the relationship between the time they spent with their children and their children's misconduct and this could lead to higher level of children misconduct as identified in previous studies (Sandberg and Hofferth, 2001); Cashwell and Vacc, 1996). As such serious effort must be taken to make parents understand their role in ensuring that their children are not involved in any activities considered as misconducts by communicating more with their children. In line with this, it is suggested that policy makers should provide more exposure in the form of training, distribution of pamphlets and brochures to parents so that they will understand vividly on parental role especially in ensuring that they allocate precious time to do activities together with their children besides talking and listening to their children problems.

Moreover, that school may take the first step by organizing more parents-child activities at school which needs involvement of both parents and children. Previous findings by Wherry (1992) in LaBahn (1995) had shown that schools are important avenue that would generate a high interaction process between parents and children. The time spent in such activities may help improve communication and thus reduce children's involvement in misconducts. Also parents themselves must take the initiatives to organize family activities during free time such as weekends and holiday. These activities may include storytelling, cooking together, as well as problem solving games that would require communication skills such as listening, reasoning, tolerance between parents and children.

\section{CONCLUSION}

In conclusion, since past research has shown that communication problem between parents and children as one of the factors that make children to feel lonely and depressed (Hartos and Power, 2000) and lead them to be involved in social misconducts and since enhanced communication between parents and children has been identified as one of the important factors that could prevent children from involved in social problems (Clark and Shields, 1997); thus, more effort should be taken to improve parents-children communication. Thus, a plan should be laid out on how to educate the parents on the importance of family communication. Among the suggestions are organizing parents-children activities at school and at home, conduct talks on parent-children communication and encourage parents to spend more time with their children by doing activities together.

\section{REFERENCES}

Alwin, D.F., 1996. From Childbearing to childrearing: The link between declines in fertility and changes in the socialization of children. Pop. Dev. Rev., 22: 176-196.

Barberet, R. and B.S. Fisher, 2009. Can security beget insecurity? Security and crime prevention awareness and fear of burglary among university students in the East Midlands. Secur. J., 22: 3-23. DOI: 10.1057/sj.2008.9

Baucom, D.H., N. Epstein, L.A. Rankin and C.K. Burnett, 1996. Assessing relationship standards: The inventory of specific relationship standards. J. Fam. Psyc., 10: 72-88. 
Bernard, E. and M.B. Fenton, 2007. Bats in a fragmented landscape: Species composition, diversity and habitat interactions in savannas of Santarem, Central Amazonia, Brazil. Biol. Conservation, 134: 332343. DOI: 10.1016/j.biocon.2006.07.021

Cashwell, C.S. and N.A. Vacc, 1996. Family functioning and risk behaviors: Influences on adolescent delinquency. Sch. Couns., 44: 105-114.

Caughlin, J.P., 2003. Family communication standards. What counts as excellent family communication and how are such standards associated with family satisfaction? Hum. Comm. Res., 29: 5-40.

Clark, R.D. and G. Shields, 1997. Family communication and delinquency. Adolescence, 32: 81-92. PMID: 9105493

Elias, $\mathrm{H}$ and N. Noordin, 2011. The influence of parents in adolescents' misbehavior. J. Soc. Sci., 7: 423-427. DOI: $10.3844 /$ jssp.2011.423.427

Emmers-Sommer, T.M., 2004. The effect of communication quality and quantity indicators on intimacy and relational satisfaction. J. Soc. Pers. Relat., 21: 399-411. DOI: $10.1177 / 0265407504042839$

Fletcher, G.J.O., J.A. Simpson, G. Thomas and L. Giles, 1999. Ideals in intimate relationships. J. Pers. Soc. Psyc., 76: 72-89. PMID: 9972554

Hartos, J.L. and T.G. Power, 2000. Association between mother and adolescent reports for assessing relations between parent-adolescent communication and adolescent adjustment. J. Youth Adolescence, 29: 441-450. DOI: 10.1023/A:1005158425861

Jolly, C., 2007. Take charge in changing times: Improving family communication. Family Life.

Klein, K., R. Forehand, L. Armistead and P. Long, 1997. Delinquency during the transition to early adulthood: Family and parenting predictors from early adolescence. Adolescence, 32: 61-81. PMID: 9105492

Knapp, M.L. and J.A. Hall, 2009. Nonverbal Communication in Human Interaction. 7th Edn., Wadsworth Publishing, ISBN-10: 0495568694, pp: 512.

Koerner, A.F. and M.A. Fitzpatrick, 1997. Family type and conflict: The impact of conversation orientation and conformity orientation on conflict in the family. Commun. Stud., 48: 59-75. DOI: 10.1080/10510979709368491

Koerner, A.F. and M.A. Fitzpatrick, 2004. Communication in Intact Families. In: Handbook of Family Communication, Vangelisti, A.L., (Ed.)., Routledge, ISBN-10: 0805841318, pp: 177-195.
LaBahn, J., 1995. Education and parental involvement in secondary schools: Problems, solutions and effects. Valdosta State University, GA.

Lingren, H.G., 1998. A new view of 'quality time'. Enriching family relationship. Ohio State University Cooperative Extension.

Mastura, L. and R. Hamzah, 2007. Asas kaunseling keluarga: Corak komunikasi berkesan. University Teknologi Mara, Shah Alam.

McLeod, J.M. and S.H. Chaffee, 2007. The Construction of Social Reality. In: The Social Influence Process, Tedeschi, J. (Ed.)., Transaction Publishers, New Brunswick, ISBN-10: 0202361497, pp: 50-59.

O'Hair, D., 1998. Strategic Communication in Business and the Professions. 3rd Edn., Cengage Learning, ISBN-10: 0395951844.

Poole, M.S., A.H.V.D. Ven, K. Dooley and M.E. Holmes, 2000. Organizational Change and Innovation Processes: Theory and Methods for Research. 1st Edn., Oxford University Press, New York, ISBN-10: 0195131983, pp: 416.

Rathus, S.A., 2010. Childhood and Adolescence: Voyage in Development. 4th Edn., Cengage Learning, Belmont, ISBN-10: 9780495904366, pp: 543.

Salleh, M.H., K. Nurani, O.S. Zobidah, A. Musa and I. Narimah et al., 2009. Family communication quality measurement index: Strategy in handling the teenagers' offences.

Sandberg, J.F. and S.L. Hofferth, 2001. Changes in children's time with parents: United states, 19811997. Demography, 38: 423-436. DOI: 10.1353/dem.2001.0031

Segrin, C. and J. Flora, 2005. Family Communication. 1st Edn., Routledge, ISBN-10: 0805847987, pp: 504.

Smith, K.V., P.A. Freeman and R.B. Zabriskie, 2009. An examination of family communication within the core and balance model of family leisure functioning. Family Relat., 58: 79-90. DOI: 10.1111/j.1741-3729.2008.00536.x

Vangelisti, A.L. and J.A. Daly, 1997. Gender differences in standards for romantic relationships. Pers. Rel., 4: 203-219. DOI: 10.1111/j.1475-6811.1997.tb00140.x

Vangelisti, A.L., L.P. Crumley and J.L. Baker, 1999. Family portraits: Stories as standards for family relationships. J. Soc. Pers. Rel., 16: 335-368. DOI: $10.1177 / 0265407599163004$

Wherry, J.H., 1992. Getting parents involved. Ed. Dig. J., 66: 34-35. 